\title{
Ecological rationality: a framework for understanding and aiding the aging decision maker
}

\author{
Rui Mata ${ }^{1}$, Thorsten Pachur ${ }^{1}$, Bettina von Helversen ${ }^{1}$, Ralph Hertwig ${ }^{1}$, Jörg Rieskamp ${ }^{1}$ and Lael Schooler ${ }^{2}$ \\ Department of Psychology, University of Basel, Basel, Switzerland \\ ${ }^{2}$ Center for Adaptive Behavior and Cognition, Max Planck Institute for Human Development, Berlin, Germany
}

\section{Edited by:}

Shu-Chen Li, Max Planck Institute for Human Development, Germany

Reviewed by:

Ming Hsu, University of California Berkeley, USA

Marieke Karlijn Van Vugt, University of Groningen, Netherlands

Kirsten G. Volz, Werner Reichardt

Centre for Integrative Neuroscience, Germany

*Correspondence:

Rui Mata, Department of Psychology, University of Basel, Missionsstrasse 64A, 4055 Basel, Switzerland. e-mail: rui.mata@unibas.ch
The notion of ecological rationality sees human rationality as the result of the adaptive fit between the human mind and the environment. Ecological rationality focuses the study of decision making on two key questions: First, what are the environmental regularities to which people's decision strategies are matched, and how frequently do these regularities occur in natural environments? Second, how well can people adapt their use of specific strategies to particular environmental regularities? Research on aging suggests a number of changes in cognitive function, for instance, deficits in learning and memory that may impact decision-making skills. However, it has been shown that simple strategies can work well in many natural environments, which suggests that age-related deficits in strategy use may not necessarily translate into reduced decision quality. Consequently, we argue that predictions about the impact of aging on decision performance depend not only on how aging affects decision-relevant capacities but also on the decision environment in which decisions are made. In sum, we propose that the concept of the ecological rationality is crucial to understanding and aiding the aging decision maker.

Keywords: aging, decision making, ecological rationality, strategy selection, strategy execution
In Cicero's de Senectute (Cicero, 1909-1914), Cato, the elder, explains to two younger men how to flourish in old age: "Nor, again, do I now miss the bodily strength of a young man (...) any more than as a young man I missed the strength of a bull or an elephant. You should use what you have, and whatever you may chance to be doing, do it with all your might." Cato seems to suggest that the key to successful aging lies not in attempting to regain the strength of youth or to mourn its loss but in using the available resources wisely, so as to meet one's own aspirations and the challenges one faces (see Baltes, 1997, for a similar perspective). Elaborating on this suggestion, we first introduce the notion of ecological rationality and suggest that the wise selection of decision strategies that fit specific ecologies is crucial to achieving good decisions (Gigerenzer et al., 1999; Gigerenzer et al., 2011; Gigerenzer and Gaissmaier, 2011; Todd et al., in press). Second, we present specific examples of how the fit between simple decision strategies and ecologies can lead to successful decision making. In particular, we review empirical findings that suggest that while age-related cognitive decline may lead to changes in the selection and execution of decision strategies, the impact of such changes is a function of the structure of the environment. Consequently, we argue that age-related deficits in strategy selection and execution may not necessarily translate into diminished decision quality. We conclude by presenting an outlook for future work on the ecological rationality of aging.

\section{ECOLOGICAL RATIONALITY: THE FIT BETWEEN MIND AND ENVIRONMENT}

The concept of ecological rationality suggests three basic tenets regarding decision making. First, the mind's decision strategies are adapted to particular environments. Therefore, decision strategies are not good or bad per se but can only be evaluated relative to the environments in which they are used. Here, we use the term environment to refer to the statistical properties of a set of objects, such as the correlations between attributes of these objects (i.e., cues) and a criterion. For example, it may be useful to describe the environment of health plans statistically as the correlation between the cost of monthly premium and the amount of coverage. Second, in certain environments, simple decision strategies are able to compete with complex strategies - less is (sometimes) more. Third, humans largely respond adaptively to task and environmental characteristics. In what follows, we provide support for these tenets and discuss their boundary conditions.

\section{THE MIND-ENVIRONMENT FIT}

According to the notion of ecological rationality, decision strategies are adapted to particular environments. Table 1 gives an overview of various strategies that differ in complexity (e.g., in terms of the amount of information considered) and the environments under which they work well. Consider the following question: Which Swiss city has more inhabitants: Geneva or Thun? The recognition heuristic (Goldstein and Gigerenzer, 2002) is an inference strategy that predicts that a recognized object, most likely Geneva and not Thun, scores higher on some criterion (population) than an unrecognized one. The recognition heuristic is a prime example of how, by exploiting a match between mind and environment (i.e., all Swiss cities), a simple algorithm can lead to efficient decision making. It uses a single cue (i.e., whether or not the person recognizes the name of two cities) to predict the cities' relative population, the criterion of interest. The heuristic is thus 
ecologically rational in this environment because the likelihood of recognition is highly correlated with a city's population. In fact, recognition may be a useful cue in many domains; cities with more inhabitants, mountains with higher peaks, and rivers with longer courses tend to be more often recognized than objects with lower values on these dimensions (Goldstein and Gigerenzer, 2002). Recognition is not always a valid cue, however. For example, the population of Swiss cities, but not, say, their distance from the city Interlaken, is correlated with recognition. As a consequence, one is well advised to use recognition when judging which of two Swiss cities is larger, but not when asked to judge which is closer to Interlaken (Pohl, 2006). In sum, the recognition heuristic illustrates the notion of mind-environment fit by showing how a simple mental mechanism can exploit the structure of specific environments.

\section{LESS CAN BE MORE}

According to common wisdom, more knowledge, more information, and more computation should lead to better decisions, while cognitive limitations pose a liability (see Hertwig and Todd, 2003). Analyses of simple strategies have shown that this is not necessarily the case. For example, a person recognizing many Swiss cities can, if recognition is a good predictor, be less accurate in judging the sizes of Swiss cities than a person recognizing fewer cities - the less-is-more effect (Goldstein and Gigerenzer, 2002; for a review, see Pachur, 2010). The reason is that if many cities are recognized, the recognition heuristic cannot be applied (because recognition does not discriminate) and other, potentially less valid predictors need to be recruited - leading to lower inferential accuracy. Similarly, simple strategies may sometimes compete with or even outperform more complex strategies. Consider, for instance, the take-the-best (TTB) heuristic, a strategy that can be recruited when recognition does not discriminate to infer which of two objects has the higher criterion value, TTB simply selects the object that is supported by the most valid predictor or "cue" (see Table 1). TTB can be highly competitive in comparison with considerably more complex strategies (e.g., Gigerenzer and Brighton, 2009). How is that possible? First, TTB can do well because in natural environments cues are often highly correlated, and thus searching for more cues does not necessarily yield new information (Dieckmann and Rieskamp, 2007; Hogarth and Karelaia, 2007). Second, TTB is less susceptible to overfitting when making predictions - that is, it does not take into account (much) unsystematic variability in the data (i.e., noise). Therefore, TTB can be a robust strategy that leads to higher generalization performance relative to more complex inference strategies, like multiple regression, neural networks, and exemplar models (see Gigerenzer and Brighton, 2009, for a discussion of how TTB avoids overfitting).

\section{ADAPTIVE DECISION MAKING}

The existence of multiple decision environments and strategies poses a fundamental problem to decision makers - that of adaptively selecting a strategy that fits the particular environment. The available evidence suggests people are by and large adaptive decision makers. For example, participants show higher reliance on the recognition heuristic when recognition is a valid cue (Pachur et al., 2011). More generally, decision makers seem to be sensitive to a number of task characteristics and adjust their strategies accordingly, including monetary information costs
(Bröder, 2000), time pressure (Rieskamp and Hoffrage, 2008), cue-criterion relations (Rieskamp and Otto, 2006), and memory demands (Bröder and Schiffer, 2003). There are, however, also boundary conditions for adaptive strategy selection. First, there are significant individual differences in adaptivity, that is, not all individuals adapt to task characteristics equally well (Bröder, 2003; Newell, 2005; Rieskamp and Otto, 2006; Rieskamp, 2008). Second, adaptivity in strategy selection is limited in dynamically changing environments (Bröder and Schiffer, 2006; Rieskamp, 2006).

\section{ECOLOGICAL RATIONALITY AND THE AGING DECISION MAKER}

How can ecological rationality inform research on the impact of aging on decision making? Research on aging suggests that there are basic structural and neuromodulatory brain changes with increased age that lead to cognitive decline and poor behavioral outcomes in several areas of functioning, such as workingmemory, episodic memory, and executive function (see Nyberg and Bäckman, 2010; Rodrigue and Kennedy, 2010, for reviews). The notion of ecological rationality, however, emphasizes the key role of the fit between (simple) strategies and environments for successful decision making and thus questions the inevitability of poor outcomes in the face of cognitive constraints. Indeed, the idea of ecological rationality suggests that superior cognitive abilities may not always be necessary or desired: Less is (sometimes) more, or at least enough (Hertwig and Todd, 2003). For example, results based on computer simulation suggest that the aging decision maker can afford to neglect information in consumer decisions because this leads to only small losses in decision quality (Mata and Nunes, 2010). Similarly, expertise research has provided demonstrations that experts often rely on less information than novices (Garcia-Retamero and Dhami, 2009), suggesting that expertise may enable superior decision performance through the use of simple strategies (see also Shanteau, 1992). In addition, there is some evidence that older adults relying on simple strategies can outperform younger adults in inference tasks for which these strategies are most appropriate (Merritt et al., 2010; Worthy and Maddox, 2012).

To the extent that people rely on simple and ecologically rational strategies, cognitive decline associated with aging need not always lead to decrements in decision-making quality. If the cognitive decline does not compromise the execution of the simple strategies, a high level of decision-making quality can be retained. Decrements, however, may occur whenever aging leads to a mismatch between the strategies used and the environments encountered. In what follows, we distinguish two ways in which aging may limit the strategy-environment fit and thus limit decision performance. First, aging may impact how well individuals can select the appropriate decision strategy for a particular task environment - the issue of strategy selection. Second, aging may impact how well individuals can execute a particular strategy in a given environment - the issue of strategy execution. Finally, we conclude by suggesting how the concept of ecological rationality can guide interventions to improve decision making in the elderly.

\section{AGE DIFFERENCES IN STRATEGY SELECTION}

Overall, research on aging and strategy selection suggests that older adults are adaptive decision makers. For instance, Pachur et al. 
Table 1 | Decision strategies, respective ecologies, and studies investigating their neural substrates.

\begin{tabular}{|c|c|c|c|}
\hline Strategy & Description & Appropriate environment & $\begin{array}{l}\text { Study investigating } \\
\text { neural substrates }\end{array}$ \\
\hline $\begin{array}{l}\text { Recognition (Goldstein } \\
\text { and Gigerenzer, 2002) }\end{array}$ & $\begin{array}{l}\text { If one of two alternatives is recognized, infer that it } \\
\text { has the higher value on the criterion. }\end{array}$ & $\begin{array}{l}\text { Recognition validity >0.5 (cf. Goldstein } \\
\text { and Gigerenzer, 2002) }\end{array}$ & $\begin{array}{l}\text { Volz et al. (2006), } \\
\text { Rosburg et al. (2011) }\end{array}$ \\
\hline $\begin{array}{l}\text { Fluency (Schooler and } \\
\text { Hertwig, 2005) }\end{array}$ & $\begin{array}{l}\text { If both alternatives are recognized but one is } \\
\text { recognized faster, infer that it has the higher value } \\
\text { on the criterion. }\end{array}$ & $\begin{array}{l}\text { Fluency validity }>0.5 \text { (cf. Schooler and } \\
\text { Hertwig, 2005) }\end{array}$ & Volz et al. (2010) \\
\hline $\begin{array}{l}\text { Take-the-best } \\
\text { (Gigerenzer and } \\
\text { Goldstein, 1996) }\end{array}$ & $\begin{array}{l}\text { To infer which of two alternatives has the higher } \\
\text { value (a) search through cues in order of validity, (b) } \\
\text { stop search as soon as a cue discriminates, and (c) } \\
\text { choose the alternative this cue favors. }\end{array}$ & $\begin{array}{l}\text { High cue redundancy (cf. Hogarth and } \\
\text { Karelaia, 2007) }\end{array}$ & Khader et al. (2011) \\
\hline Tallying (Dawes, 1979) & $\begin{array}{l}\text { To infer which of two alternatives has the higher } \\
\text { value, count the number of positive cues of each } \\
\text { alterative and choose the one with the higher sum. }\end{array}$ & $\begin{array}{l}\text { Low cue redundancy, uncertainty } \\
\text { about cue weights (cf. Hogarth and } \\
\text { Karelaia, 2007) }\end{array}$ & - \\
\hline $\begin{array}{l}\text { Weighted additive } \\
\text { (Payne et al., 1993) }\end{array}$ & $\begin{array}{l}\text { To infer which of two alternatives has the higher } \\
\text { value, multiply each cue value by the respective } \\
\text { cue weight, sum the results for each alternative, } \\
\text { and choose the one with the higher sum. }\end{array}$ & $\begin{array}{l}\text { Low cue redundancy, good knowledge } \\
\text { about cue weights }\end{array}$ & - \\
\hline
\end{tabular}

(2009) showed that both younger (Mean age $=24$, range $=19-33$ ) and older adults $(M=70$, range $=65-86)$ rely more on recognition in an environment in which recognition is highly predictive of the criterion (i.e., cities) than when it is not (i.e., diseases). This environment or task adaptivity has been demonstrated in other studies: Older adults adjust their search and decision strategies according to the amount of information available (Mata and Nunes, 2010), and cue-criterion relations (Mata et al., 2007, 2010). For example, Mata et al. (2007) asked younger $(M=24$, age range $=18-37)$ and older adults $(M=71,64-90)$ to make decisions in (a) a compensatory environment, in which all cues were equally predictive of a criterion or in (b) a non-compensatory environment, in which there was a clear ranking of cue importance. In the former, information-intensive strategies are appropriate, whereas the latter favors simple strategies (because some information may be ignored without leading to a performance decrement). Both younger and older adults tended to rely more on simpler strategies, such as TTB, in the appropriate non-compensatory environment, in which information could be ignored without sacrificing inferential accuracy. In sum, consistent with the concept of ecological rationality, most younger and older adults seem to be aware that simpler decision strategies can lead to satisfactory outcomes in some environments and adjust their strategy selection accordingly (Mata et al., 2007, 2010; Pachur et al., 2009).

Nevertheless, there is some indication that older adults have more difficulties in adapting their strategy selection as a function of environment characteristics relative to younger adults. In other words, aging may attenuate but not eliminate the ability to select strategies adaptively. Specifically, older adults in Mata et al. (2007) relied more on simpler strategies regardless of the environment. Importantly, this was related to individual differences in fluid abilities, suggesting that age-related cognitive decline may have limited access to more complex strategies. In addition, adaptive strategy selection in older adults also seems to be constrained by learning deficits. Mata et al. (2010) found that older adults $(M=69,60-$ 79) had more difficulties with strategy selection learning on the basis of performance feedback relative to younger adults $(M=24$, 19-34). A meta-analysis by Mata et al. (2011b) on differences between younger and older adults' decision making under risk supported this finding. Specifically, the analysis revealed systematic age differences in risk taking in tasks where the probabilities of outcomes had to be learned from repeated exposure (decisions from experience). In contrast, although there were some significant differences between age groups, no systematic pattern arose in the tasks where probabilities and outcomes were conveniently summarized to decision makers (decisions from description). These results converge with behavioral, computational, and neuroimaging analyses showing age differences in reward learning, possibly linked to age-related decline in neuromodulatory efficiency such as dopaminergic function (e.g., Mutter et al., 2007; Mell et al., 2009; Samanez-Larkin et al., 2011).

Another aspect of successful strategy selection concerns item or trial-by-trial adaptivity (cf. Pachur, 2011). For example, despite its simplicity, the adaptive use of the recognition heuristic requires several abilities, including the ability to recognize objects but also the ability to assess whether recognition is a useful indicator in a particular environment or for a specific item. An investigation of the neural processes involved in applying the recognition heuristic supports the postulation of such distinct processes. Volz et al. (2006) examined the neurological underpinnings of the recognition heuristic using functional magnetic resonance imaging (fMRI). In this study participants repeatedly had to indicate which of two cities they thought was larger. When a decision could be made based on recognition, there was activation in the medial parietal cortex, which can be attributed to reliance on recognition memory. In addition, there was independent activation in the anterior frontomedial cortex (aFMC), a brain area involved in evaluating internal states, including self-referential processes and 
social-cognitive judgments (e.g., relating an aspect of the external world to oneself). The processes underlying this aFMC activation are likely associated with evaluating whether recognition is a useful cue in the current judgment situation. Importantly, behavioral evidence suggests that this evaluation process requires considerable cognitive resources. Pachur and Hertwig (2006) asked participants to judge which of two infectious diseases is more prevalent, a decision environment in which recognition has low validity. It turned out that inferences were more likely to follow recognition under time pressure than without time pressure. This suggests that evaluating whether recognition should be applied on a specific item is an effortful process that requires some time.

Given the cognitive costs necessary to adaptively suspend the recognition heuristic on a trial-by-trial basis, older adults may fare worse than younger adults in doing so. Evidence for such age-related decrements in item adaptivity was found by Pachur et al. (2009). Investigating younger and older German adults' use of recognition in judging the relative frequency of diseases, it was shown that older adults were constrained in their ability to adaptively suspend the recognition heuristic on specific items for which recognition was not a good cue. For example, the disease Leprosy is recognized by most individuals but is also known to be practically extinct in the German population. As a result, one will do well to bet against recognition when faced with a pair involving Leprosy and some other unrecognized disease - but older adults were less able to do so, often picking the recognized disease. Importantly, these age differences were partly mediated by individual differences in fluid cognitive abilities, suggesting that age-related cognitive decline drives the age-related deficit in adaptive strategy selection (suspension) of the recognition heuristic on a trial-by-trial basis. Based on the results by Volz et al. (2006), one may hypothesize that age differences in the suspension of the recognition heuristic are mediated by frontal structures such as the aFMC. Future work in the decision neuroscience of aging could thus inform the debate concerning the impact of aging on adaptive strategy selection.

In sum, both young and older adults seem to adjust their strategy selection as a function of environment structure (environment or task adaptivity). Nevertheless, age-related decline in fluid abilities including learning deficits may somewhat constrain the strategies available to older participants and the ability to adjust strategy selection on a trial-by-trial basis (item or trial-by-trial adaptivity).

\section{AGE DIFFERENCES IN STRATEGY EXECUTION}

Selecting the right strategy for a given problem is a necessary but not sufficient condition for successful decision making. To make the right choice one must also be able to execute the strategy correctly. Some findings suggest that aging can lead to difficulties in strategy execution. Mata et al. (2010) used a computational model to decompose the strategy selection learning process of younger and older adults, which included a strategy execution component. The results suggest that there are considerable age differences in the execution errors of younger and older adults and that these differ by strategy: Older adults showed increased strategy execution errors relative to younger adults particularly in an environment favoring complex strategies that require extensive integration and weighing of information. Similar age differences in strategy execution have been reported in studies that explicitly instructed younger and older adults to apply decision strategies (e.g., Bruine de Bruin et al., 2007).

An additional factor mediating age differences in strategy execution may be the way in which decision-relevant information is represented - such as whether decisions are made from tabulated information or from memory. Retrieving information from memory can sometimes be an effortful process requiring considerable involvement of control structures. In a neuroimaging study, Khader et al. (2011) monitored the activation of specific representations of attribute knowledge in long-term-memory with fMRI while participants made memory-based decisions using TTB. The amount of information required for a decision was reflected in activation of the dorsolateral prefrontal cortex (dlPFC) and this activation seemed to modulate posterior areas responsible for memory storage. Because aging is associated with deficits in some frontal control structures as well as storage components of memory (Nyberg and Bäckman, 2010; Spreng et al., 2010) it is likely that older adults show difficulties in the selective retrieval of information in decisions from memory. Indeed, older adults seem to avoid strategies that rely heavily on memory retrieval in inference tasks (i.e., exemplar processing; Mata et al., 2011a). Neuroimaging studies focusing on the neural substrates of memory retrieval during decision making could help to better understand the contribution of frontal and posterior areas to age differences in decisions from memory.

Summing up, age-related cognitive decline may lead to deficits in strategy execution but these effects are likely to be moderated by strategy and task complexity, for example, the memory requirements of the task.

\section{AIDING THE AGING DECISION MAKER}

There is considerable interest in cognitive enhancement of the elderly (Hertzog et al., 2009), as well as in reducing the learning and memory requirements of decision tasks to reduce age differences in decision performance (Samanez-Larkin et al., 2011). However, as suggested above, the notion of ecological rationality suggests that enhancing cognitive abilities may not always be necessary or desired: Simple strategies can often do as well or even better than more complex ones (Gigerenzer and Brighton, 2009). Accordingly, rather than simply enhancing cognition, we must aim at identifying the specific situations that benefit from such enhancements to ensure successful decision making by the elderly. For example, we predict that enhancing older adults' fluid abilities could lead to improvements in decision quality in environments that require the integration of many pieces of information, and thus favor the use of complex decision strategies. In contrast, cognitive enhancement should not benefit and could even hinder performance in environments in which simple strategies work well, for example, in non-compensatory environments (Mata et al., 2007, 2011b; see also Hills and Hertwig, 2011).

The notion of ecological rationality also implies that enhancing the strategy-environment fit is key to improving decision making. One way to do this is to inform or train participants about the link between particular strategies and environments. Alternatively, one may want to change the task characteristics to fit the decision strategies of the elderly. For example, the provision of clear cue 
rankings may facilitate the subsequent use of non-compensatory strategies. No doubt more effort needs to be invested in understanding how task and environment characteristics can be used to improve decisions (Hibbard and Peters, 2003; Thaler and Sunstein, 2008).

\section{OUTLOOK}

Linking evidence from behavioral, computational, and neural analyses seems crucial to fully understand how aging impacts decision making. Unfortunately, to our knowledge there has been no work examining how aging impacts the neural substrates responsible for the selection or execution of decision strategies, and computational modeling in this domain is in its infancy. There is perhaps something to be gained by informing the study of the ecological rationality of aging through insights from more researched domains, such as arithmetic skill or memory (Lemaire, 2010; Nyberg and Bäckman, 2010).

Second, more work is needed to understand the factors that determine age differences in strategy selection. While most work emphasizes cognitive constraints, others suggest important

\section{REFERENCES}

Baltes, P. B. (1997). On the incomplete architecture of human ontogeny: selection, optimization, and compensation as foundation of developmental theory. Am. Psychol. 52, 366-380.

Bröder, A. (2000). Assessing the empirical validity of the "take-thebest" heuristic as a model of human probabilistic inference. $J$. Exp. Psychol. Learn. Mem. Cogn. 26, 1332-1346.

Bröder, A. (2003). Decision making with the "adaptive toolbox": influence of environmental structure, intelligence, and working memory load. J. Exp. Psychol. Learn. Mem. Cogn. 29, 611-625.

Bröder, A., and Schiffer, S. (2003). "Take the best" versus simultaneous feature matching: probabilistic inferences from memory and effects of representation format. J. Exp. Psychol. Gen. 132, 277-293.

Bröder, A., and Schiffer, S. (2006). Adaptive flexibility and maladaptive routines in selecting fast and frugal decision strategies. J. Exp. Psychol. Learn. Mem. Cogn. 32, 904-918.

Bruine de Bruin, W., Parker, A., and Fischhoff, B. (2007). Individual differences in adult decision-making competence (A-DMC). J. Pers. Soc. Psychol. 92, 938-956.

Cicero. (1909-1914). On Old Age, Vol. 9, Part 2, trans. E. S. Shuckburgh. New York: P. F. Collier and Son.

Dawes, R. M. (1979). The robust beauty of improper linear models in decision making. Am. Psychol. 34, 571-582.
Dieckmann, A., and Rieskamp, J. (2007). The influence of information redundancy on probabilistic inferences. Mem. Cognit. 35, 1801-1813.

Garcia-Retamero, R., and Dhami, M. K. (2009). Take-the-best in expertnovice decision strategies for residential burglary. Psychon. Bull. Rev. 16, 163-169.

Gigerenzer, G., and Brighton, $\mathrm{H}$. (2009). Homo heuristicus: why biased minds make better inferences. Top. Cogn. Sci. 1, 107-143.

Gigerenzer, G., and Gaissmaier, W. (2011). Heuristic decision making. Annu. Rev. Psychol. 62, 451-482.

Gigerenzer, G., and Goldstein, D. G. (1996). Reasoning the fast and frugal way: models of bounded rationality. Psychol. Rev. 103, 650-669.

Gigerenzer, G., Hertwig, H., and Pachur, T. (2011). Heuristics: The Foundations of Adaptive Behavior. New York: Oxford University Press.

Gigerenzer, G., Todd, P. M., and The ABC Research Group. (1999). Simple Heuristics that Make Us Smart. New York: Oxford University Press.

Goldstein, D. G., and Gigerenzer, G. (2002). Models of ecological rationality: the recognition heuristic. Psychol. Rev. 109, 75-90.

Hanoch, Y., Wood, S., and Rice, T. (2007). Bounded rationality, emotions and older adult decision making: not so fast and yet so frugal. Hum. Dev. 50, 333-358.

Hertwig, R., and Todd, P. M. (2003). "More is not always better: the benefits of cognitive limits," in Thinking: Psychological Perspectives

goal-related and motivational aspects. For example, there may be systematic differences in how younger and older adults approach decision problems, with older adults tending to emphasize accuracy over speed (Ratcliff et al., 2007) or the valence of information (Hanoch et al., 2007).

Finally, the work reviewed above mostly concerns age differences observed in laboratory studies and artificial stimuli (see Pachur et al., 2009, for an exception). Consequently, we know relatively little about the natural decision environments of young and older adults, or differences in the representation of environments by different age groups. An ecological analysis of the decision environments that older adults face is necessary to assess the adaptivity of the specific decision strategies used. For example, do older adults or those looking out for them actively select or engineer environments so as to enable the use of simple strategies? Only by gaining a better understanding of both older adults' decision strategies and ecologies will we be able to provide decision aids and redesign environments that support good decisions. We can thus hope to fulfill Cicero's vision of successful aging by matching older adults' resources to the structure of their decision environments.

on Reasoning, Judgment and Decision Making, eds D. Hardman and L. Macchi (Chichester: Wiley), 213-231.

Hertzog, C., Kramer, A. F., Wilson, R. S., and Lindenberger, U. (2009). Enrichment Effects on Adult Cognitive Development: Can the Functiona Capacity of Older Adults be Preserved and Enhanced? Psychological Science in the Public Interest, Vol. 9, Whole No. 1. Washington, DC: Association for Psychological Science.

Hibbard, J. H., and Peters, E. (2003). Supporting informed consumer health care choices: data presentation approaches that facilitate the use of information in choice. Annu. Rev. Public Health 24, 413-433.

Hills, T., and Hertwig, R. (2011). Why aren't we smarter already? Evolutionary trade-offs and cognitive enhancements. Curr. Dir. Psychol. Sci. 20, 373-377.

Hogarth, R. M., and Karelaia, N. (2007). Heuristic and linear models of judgment: matching rules and environments. Psychol. Rev. 114, 733-758.

Khader, P., Pachur, T., Meier, S., Bien, S., Jost, K., and Rösler, F. (2011). Memory-based decision making with heuristics: evidence for a controlled activation of memory representations. J. Cogn. Neurosci. 23, 3540-3554.

Lemaire, P. (2010). Cognitive strategy variations during aging. Curr. Dir. Psychol. Sci. 19, 363-369.

Mata, R., Helversen, B., and Rieskamp, J. (2010). Learning to choose: cognitive aging and strategy selection learning in decision making. Psychol. Aging 25, 299-309.
Mata, R., and Nunes, L. (2010). When less is enough: cognitive aging, information search, and decision quality in consumer choice. Psychol. Aging 25, 289-298.

Mata, R., Schooler, L., and Rieskamp, J. (2007). The aging decision maker: cognitive aging and the adaptive selection of decision strategies. Psychol. Aging 22, 796-810.

Mata, R., von Helversen, B., Karlsson, L., and Cüpper, L. (2011a). Adult age differences in categorization and multiple-cue judgment. Dev. Psychol. PMID: 22059450. [Epub ahead of print].

Mata, R., Josef, A., Samanez-Larkin, G. R., and Hertwig, R. (2011b). Age differences in risky choice: a metaanalysis. Ann. N. Y. Acad. Sci. 1235, 18-29.

Mell, T., Wartenburger, I., Marschner, A., Villringer, A., Reischies, F. M., and Heekeren, H. R. (2009). Altered function of ventral striatum during reward-based decision making in old age. Front. Hum. Neurosci. 3:34. doi: 10.3389/neuro.09.034. 2009

Merritt, A., Karlsson, L., and Cokely, E. T. (2010). "Category learning and adaptive benefits of aging," in Proceedings of the 32nd Annual Conference of the Cognitive Science Society, Portland.

Mutter, S. A., Strain, L. M., and Plumlee, L. F. (2007). The role of age and prior beliefs in contingency judgment. Mem. Cognit. 35, 875-884.

Newell, B. R. (2005). Re-visions of rationality? Trends Cogn. Sci. (Regul. Ed.) 9, 11-15. 
Nyberg, L., and Bäckman, L. (2010). "Memory changes and the aging brain: a multimodal imaging approach," in Handbook of the Psychology of Aging, 7th Edn, eds K. W. Schaie and S. L. Willis (San Diego: Elsevier Press), 121-133.

Pachur, T. (2010). Recognition-based inference: when is less more in the real world? Psychon. Bull. Rev. 17, 589-598.

Pachur, T. (2011). The limited value of precise tests of the recognition heuristic. Judgm. Decis. Mak. 6, 413-422.

Pachur, T., and Hertwig, R. (2006). On the psychology of the recognition heuristic: retrieval primacy as a key determinant of its use. J. Exp. Psychol. Learn. Mem. Cogn. 32, 983-1002.

Pachur, T., Mata, R., and Schooler, L. (2009). Cognitive aging and the adaptive use of recognition in decision making. Psychol. Aging 24, 901-915.

Pachur, T., Todd, P. M., Gigerenzer, G., Schooler, L. J., and Goldstein, D. G. (2011). The recognition heuristic: a review of theory and tests. Front. Cogn. Sci. 2:147. doi: 10.3389/fpsyg.2011. 00147

Payne, J. W., Bettman, J. R., and Johnson, E. J. (1993). The Adaptive Decision Maker. Cambridge: Cambridge University Press.
Pohl, R. (2006). Empirical tests or the recognition heuristic. J. Behav. Decis. Mak. 19, 251-271.

Ratcliff, R., Thapar, A., and McKoon, G. (2007). Application of the diffusion model to two-choice tasks for adults 75-90 years old. Psychol. Aging 22, 56-66.

Rieskamp, J. (2006). Perspectives of probabilistic inferences: reinforcement learning and an adaptive network compared. J. Exp. Psychol. Learn. Mem. Cogn. 32, 1355-1370.

Rieskamp, J. (2008). The importance of learning when making inferences. Judgm. Decis. Mak. 3, 261-277.

Rieskamp, J., and Hoffrage, U. (2008). Inferences under time pressure: how opportunity costs affect strategy selection. Acta Psychol. (Amst.) 127, 258-276.

Rieskamp, J., and Otto, P. E. (2006). SSL: a theory of how people learn to select strategies. J. Exp. Psychol. Gen. 135, 207-236.

Rodrigue, K. M., and Kennedy, K. M. (2010). “The cognitive consequences of structural changes to the aging Brain," in Handbook of the Psychology of Aging, 7th Edn, eds K. W. Schaie and S. L. Willis (San Diego: Elsevier Press), 121-133.

Rosburg, T., Mecklinger, A., and Frings, C. (2011). When the brain decides: a familiarity-based approach to the recognition heuristic as evidenced by event-related brain potentials. Psychol. Sci. 22, 1527-1534.
Samanez-Larkin, G. R., Wagner, A. D., and Knutson, B. (2011). Expected value information improves financial risk taking across the adult life span. Soc. Cogn. Affect. Neurosci. 6, 207-217.

Schooler, L. J., and Hertwig, R. (2005). How forgetting aids heuristic inference. Psychol. Rev. 112, 610-628.

Shanteau, J. (1992). How much information does an expert use? Is it relevant? Acta Psychol. (Amst.) 81 75-86.

Spreng, R. N., Wojtowicz, M., and Grady, C. (2010). Reliable differences in brain activity between young and old adults: a quantitative meta-analysis across multiple cognitive domains. Neurosci. Biobehav. Rev. 34, 1178-1194.

Thaler, R. H., and Sunstein, C. R. (2008). Nugde: Improving Decisions about Health, Wealth, and Happiness. New Haven: Yale University Press.

Todd, P., Gigerenzer, G., and the ABC Research Group (in press). Ecological Rationality: Intelligence in the World. New York: Oxford University Press.

Volz, K. G., Schooler, L. J., Schubotz, R. I., Raab, M., Gigerenzer, G., and von Cramon, D. Y. (2006). Why you think Milan is larger than Modena: neural correlates of the recognition heuristic. J. Cogn. Neurosci. 18, 1924-1936.

Volz, K. G., Schooler, L. J., and von Cramon, D. Y. (2010). It just felt right: the neural correlates of the fluency heuristic. Conscious. Cogn. 19, 829-837.

Worthy, D. A., and Maddox, W. T. (2012). Age-based differences in strategy use in choice tasks. Front. Neurosci. 5:145. doi: 10.3389/fnins.2011.00145

Conflict of Interest Statement: The authors declare that the research was conducted in the absence of any commercial or financial relationships that could be construed as a potential conflict of interest.

Received: 15 October 2011; accepted: 23 January 2012; published online: 14 February 2012.

Citation: Mata R, Pachur T, von Helversen B, Hertwig $R$, Rieskamp $J$ and Schooler L (2012) Ecological rationality: a framework for understanding and aiding the aging decision maker. Front. Neurosci. 6:19. doi: 10.3389/fnins.2012.00019

This article was submitted to Frontiers in Decision Neuroscience, a specialty of Frontiers in Neuroscience.

Copyright (C) 2012 Mata, Pachur, von Helversen, Hertwig, Rieskamp and Schooler. This is an open-access article distributed under the terms of the Creative Commons Attribution Non Commercial License, which permits noncommercial use, distribution, and reproduction in other forums, provided the original authors and source are credited. 